\title{
COMPARISON OF THE QUALITIES OF ATTENTION BETWEEN STUDENTS FROM THE UNWE, PRACTICING BASKETBALL IN EDUCATIONAL GROUPS AND REPRESENTATIVE TEAM
}

\author{
S. Stavrev* \\ Department „Physical Education and Sports“, University of National and World Economy \\ (UNWE), Sofia, Bulgaria
}

\begin{abstract}
Often, in our daily round we hear expressions like „he is not concentrated enough“,,he is not focused“, "he is very distracted", and etc. All these expressions speak about the importance of quality attention, with its two forms - concentration and steadiness. Scientifically, these qualities are established as significant for a number of professions, and the good professional realization of people depends on their level of development. This is the one that motivated us to investigate these qualities with students - future economists from the UNWE and the possibility to establish the level of their development at the beginning of the educational year. We have set the task to compare these qualities between two groups of students - these from the educational groups on basketball from "Physical culture" subject and students from basketball representative team of the university. The average levels of concentration and steadiness of the attention of both aggregates have been investigated and established. The level of development and variability of indices of concentration and steadiness of attention with students has been defined. Values of the variation coefficient define the groups as comparatively homogeneous with both indications, excepting the steadiness of attention with basketball players, whose results for V\% define the group as heterogeneous. Statistically reliable differences in the results have not been established on both investigated indications. Specific recommendations have been made for the future work with the educational groups and the representative basketball team of the UNWE, reporting the results got.
\end{abstract}

Key words: students, concentration and steadiness of attention, profession significant qualities

\section{INTRODUCTION}

The role and significance of sport for society are beyond any doubt since a long time ago. A well-known fact is a phrase ,,Sport is a social phenomenon". The multiple benefits for people doing sport activity on professional, semi-amateur and amateur levels have been investigated. Such are the healthy influence on the individual, creating of hygiene habits, discipline and upbringing, contacts and communicating between the team-mates and colleagues, and etc. Another, still more frequent role assigned to the sport is gaining

\footnotetext{
*Correspondence to: Spas Stavrev, University of national and world economy (UNWE), Sofia, Bulgaria, Department ,,Physical education and sports“, 1700, Sofia, Studentski grad, Email:stavrevspas@hotmail.com; stavrevspas@unwe.bg, Mobile: +359(0) 889788 861
}

and perfection of qualities, directly connected to the future adequate professional realization and increasing of the working capability of individuals. For improving the well-known, significant for the profession qualities, of importance is to establish them first, for professions of interest to us. I. Stavreva has established the significant physical and intellectual qualities for experts in the mining industry (1). I. Stavreva and S. Stavrev investigate professiogrammes establishing the significant for both professions motor and intellectual qualities - those of the economist and expert at the mining industry. Comparing these qualities they define the coincidences and differences depending on the specifics of the activity. Despite all, the important motor and intellectual qualities overlap to a greater extent (2). In a survey carried out, it has been established that in the process of active participation of students in the various sports, 
very valuable, general and special physical qualities are built up, such as force, speed, endurance, dexterity, flexibility, explosive force, speed endurance and etc. necessary for the future profession (3).

The qualities, established as important, both for the sport and economic professions (and not only) are differentiated as concentration and steadiness of attention (4). I. Stavreva investigates professiogrammes for engineers in the mining sector and underlines the significant for the profession qualities - motor, psychic and personality, characteristics of attention being between them. She proves the effectiveness of training on physical culture for building up and perfection of these qualities (5). Another author compares the concentration and steadiness of attention with students from basketball and volleyball educational groups in the UE - Varna. Individuals doing basketball sport domineer over the groups on volleyball with both indices, but these results are not supported statistically (6). In a survey on students from basketball and volleyball male teams of the UNWE - Sofia, the average levels of concentration and steadiness of attention of the contestants have been established. The levels of development and variability of these indices have been defined. Values of variation coefficient define the teams as comparatively homogeneous with both indications, excepting the steadiness of attention with basketball players, whose results define the group as nonhomogeneous. Statistically reliable differences in the results have not been established with both investigated indications (7). With another similar investigation of female students, practicing table tennis and mass aerobics, the girls from the table tennis groups at the UNWE, have shown better results with the concentration of attention (8). A. Bozhkova, G. Dyakova and S. Stavrev compare the two characteristics of attention of students from the UE - Varna and UNWE. The average values at the investigation of concentration of attention are $34,9 \mathrm{~s}$ for the students from the UNWE and $35,25 \mathrm{~s}$ for the UE - Varna. As regards the steadiness of attention, the average achievements are 0,99 for the UNWE and 1,22 for the UE-Varna. Results reveal extremely high steadiness of attention with the students from the UNWE. Considerably poorer are the results on this index with the students from the UE - Varna (9). Concentration and steadiness of attention of female volleyball players from the team of UNWE on the finals at the students' championship has been investigated by R. Arsova. She has established that both indices are stable and on a good level, prior official matches (10).

We have directed our investigation to the qualities, - concentration and steadiness of attention, as significant for the profession of economic specialties. Significant for the profession qualities are those necessary motor qualities, skills and habits that are acquired and improved in the process of education and at the professional activity alone. (11)

Comparison of the level of development of significant for the profession qualities between students from the UNWE practicing basketball in educational groups from „Physical education" subject and the representative basketball team of the university, has not been investigated yet.

\section{PURPOSE}

The aim is to establish the level of development of concentration and steadiness of attention, as significant for the profession qualities, between two groups of students, practicing one and the same sport, but at different intensity and frequency.

The tasks, we have set are the following:

1. To establish the average levels and variability of concentration and steadiness of attention with students of both investigated aggregates;

2. To compare the results of the investigated qualities between the two groups of students and to establish the reliability of differences in the indices;

3. To make conclusions and recommendations for future work with the educational groups and the representative basketball team, proceeding from the results got.

\section{METHODS}

The investigation was carried out in the beginning of the educational year 2019/2020. Target of the investigation were 15 studentssportsmen from the representative basketball team of the UNWE and 34 students (men) from basketball educational groups of „Physical education“" subject, in the UNWE.

Schulte test has been used. Five Tables with numbers from 1 to 25 in different combinations, in consecutive order. They are of size $16 \times 16 \mathrm{~cm}$. From the investigated person 
it is expected to find out on the Tables, to count loudly and show in ascending order each of the numbers from the respective series. Time in seconds for the fulfillment of the task is reported, using a chronometer for the purpose. For defining the level of concentration of attention, the average arithmetical time for indicating the numbers from Tables Nos. 2, 3, 4 and 5 are taken (12).

The steadiness of attention is defined by reporting the correlation of the result from Table No. 5 to Table No.2. The nearer the result got is to 1 (one), the better the steadiness of the attention of the investigated person is (12).

Results from the investigation have been processed, applying the following mathematical-statistical methods:
- Variation analysis - for defining the average levels and variability of the investigated indices with each of the investigated aggregates;

- Comparative t-criterion of Student for proving the significance of differences between the average levels of the investigated indications at the level of reliability $\mathrm{P}(\mathrm{t}) \geq 95 \%$.

\section{RESULTS}

It is deemed that the scattering of the indication is insignificant (the excerpt is homogeneous), when the value of the coefficient of variation is up to $10 \%$. Between 10 and $30 \%$, the excerpt is approximately homogeneous. When it is over $30 \%$, the scattering of the indication is big and the excerpt is strongly non-homogeneous (13).

Table 1. Average values and coefficients of variability of the investigated indices of students from the educational groups and representative team doing basketball sport

\begin{tabular}{|c|c|c|c|c|c|c|c|c|c|c|}
\hline $\begin{array}{c}\text { SPORT - } \\
\text { Basketball }\end{array}$ & $\begin{array}{l}\text { Investigated } \\
\text { indices }\end{array}$ & $\mathbf{n}$ & $\underset{\min }{\mathbf{X}}$ & $\underset{\max }{\mathbf{X}}$ & $\mathbf{R}$ & $\overline{\mathrm{X}}$ & $\mathbf{S}$ & V\% & As & Ex \\
\hline $\begin{array}{l}\text { Educational } \\
\text { group }\end{array}$ & \multirow{2}{*}{$\begin{array}{c}\text { Concentration } \\
\text { of attention }\end{array}$} & 34 & 18,78 & 43,65 & 24,87 & 31,16 & 6,35 & 20,37 & 0,173 & $-0,661$ \\
\hline $\begin{array}{l}\text { Representative } \\
\text { team }\end{array}$ & & 15 & 22,55 & 41,28 & 22,5 & 29,74 & 5,44 & 18,29 & 0,846 & 0,55 \\
\hline $\begin{array}{l}\text { Educational } \\
\text { group }\end{array}$ & \multirow{2}{*}{$\begin{array}{l}\text { Steadiness of } \\
\text { attention }\end{array}$} & 34 & 0,77 & 1,32 & 0,55 & 1,01 & 0,12 & 12,30 & 0,335 & $-0,077$ \\
\hline $\begin{array}{l}\text { Representative } \\
\text { team }\end{array}$ & & 15 & 0,77 & 2,05 & 1,28 & 1,09 & 0,36 & 33,10 & 2,185 & 5,558 \\
\hline
\end{tabular}

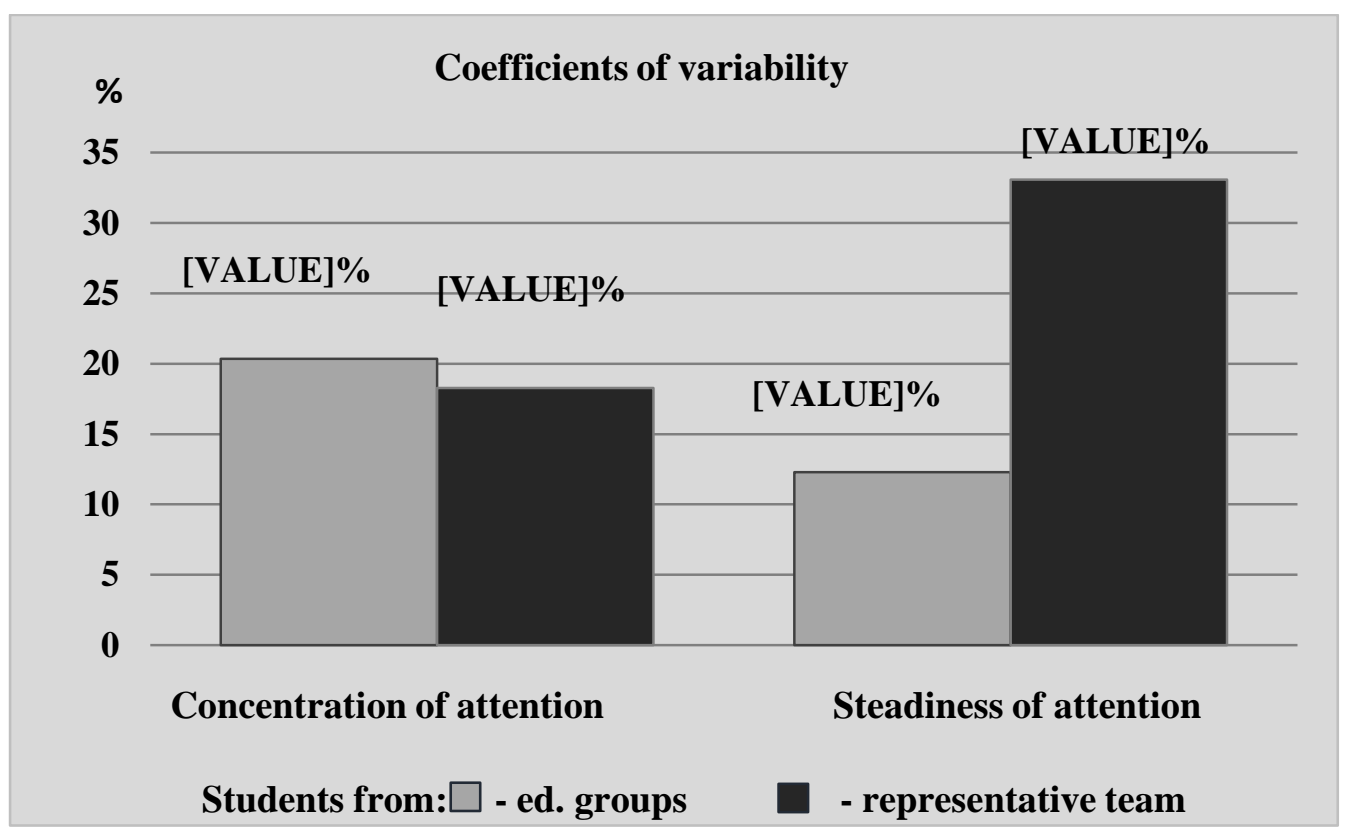

Figure 1. Coefficients of variation for both investigated indices of students from basketball educational groups and the representative team at the UNWE 
After the tests carried out and their statistical processing, we have got results for the average levels and variability of the investigated indices. In Table 1, the results after applying the variation analysis for the index concentration of attention have been shown. The minimum result of students from the educational group is better than that of the representative team, but the spread of the results $\mathrm{R}$ is by $2,82 \mathrm{~s}$ bigger for this group. Higher is the average result of students from the educational groups, which in this case is the poorer achievement. The values of the coefficient of variation on the index for a concentration of attention are $20,37 \%$ versus $18,29 \%$ for students from the representative team. Despite the difference got for $\mathrm{V} \%$, the values on this index define the two groups as comparatively homogeneous. (Figure 1)
With the index steadiness of attention, the minimum results got (Table 1) are of equal values ( $\mathrm{X} \min =0,77)$. The spread of the result on this index for students from the representative team is twice bigger $(\mathrm{R}=1,28)$ than that of students from the educational group $(0,55)$. These big amplitudes in the results of students from the basketball representative team lead to a coefficient of thevariation for steadiness of attention $\mathrm{V}=33,10 \%$, defining the group as very heterogeneous. The value got of variation coefficient for students from the educational group is $12,30 \%$. This result defines the group as comparatively homogeneous, with a result close to that for homogeneity of the groups.

Table 2. Reliability of differences with investigated indices of students from educational groups and basketball representative team

\begin{tabular}{|c|c|c|c|c|c|c|c|c|c|c|}
\hline \multirow[t]{2}{*}{$\begin{array}{l}\text { Investigated } \\
\text { indices }\end{array}$} & \multirow[t]{2}{*}{$\mathbf{n}$} & \multicolumn{2}{|c|}{$\begin{array}{l}\text { Basketball } \\
\text { educational } \\
\text { groups }\end{array}$} & \multirow[t]{2}{*}{$\mathbf{n}$} & \multicolumn{2}{|c|}{$\begin{array}{l}\text { Representative } \\
\text { basketball team }\end{array}$} & \multicolumn{2}{|c|}{ DIFFERENCES } & \multicolumn{2}{|c|}{$\begin{array}{c}\text { Statistical } \\
\text { significance }\end{array}$} \\
\hline & & $\overline{\mathrm{X}} 1$ & S1 & & $\overline{\mathrm{X}} 2$ & S2 & d & $d \%$ & $\mathbf{t}$ & $\mathbf{P}(\mathbf{t}) \%$ \\
\hline $\begin{array}{l}\text { Concentration } \\
\text { of attention }\end{array}$ & 34 & 31,16 & 6,35 & 11 & 29,51 & 5,25 & 1,42 & 4,68 & 0,66 & 48,96 \\
\hline $\begin{array}{l}\text { Steadiness of } \\
\text { attention }\end{array}$ & 34 & 1,01 & 0,12 & 11 & 1,08 & 0,34 & $-0,08$ & 7,82 & 1,11 & $\mathbf{7 2 , 7 1}$ \\
\hline
\end{tabular}

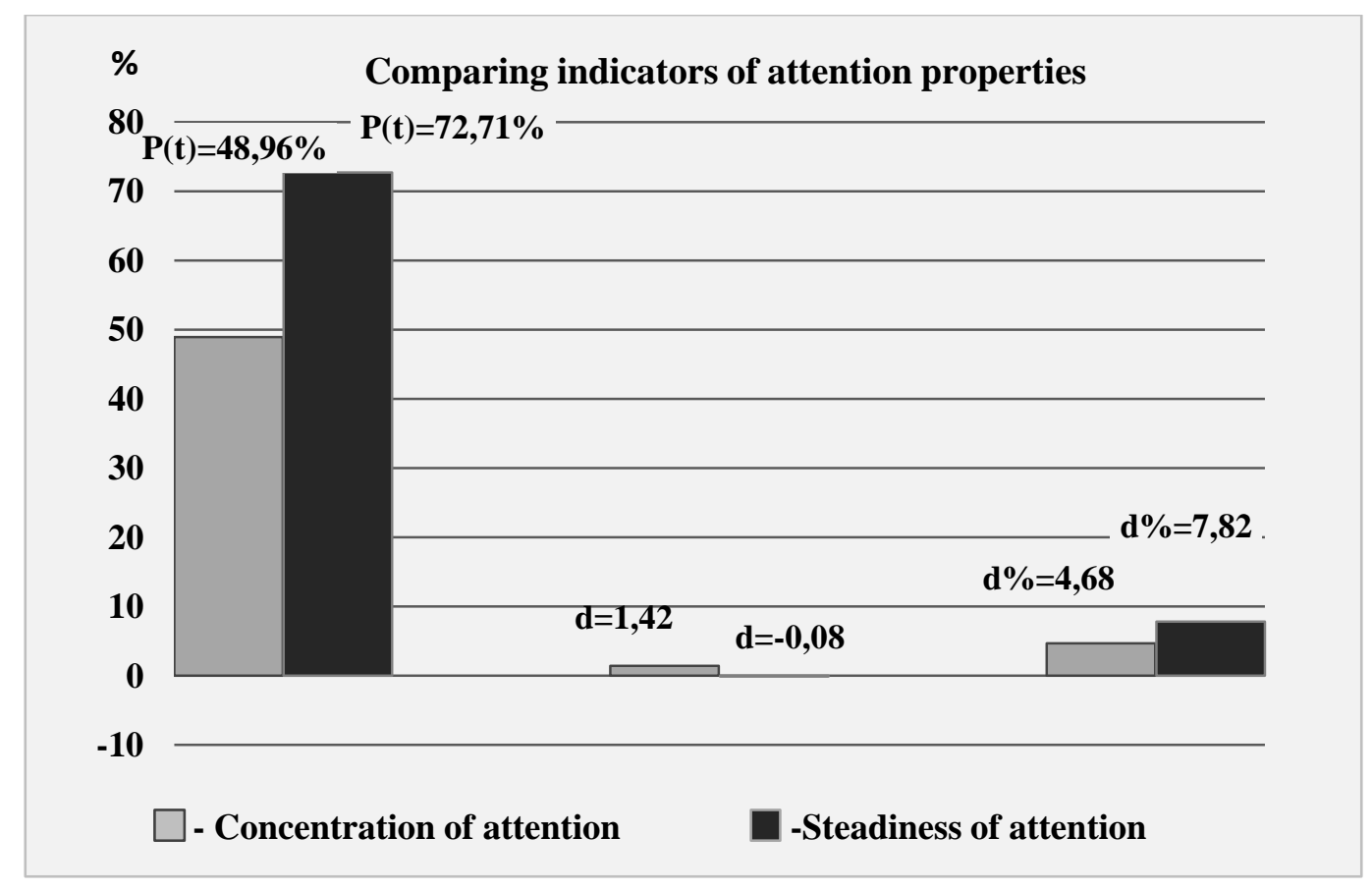

Figure 2. Comparison of the results got between students from basketball educational groups with those of the representative team 
For proving the significance of differences between the average levels of the investigated indications at level of reliability $\mathrm{P}(\mathrm{t}) \geq 95 \%$, we have subjected the results to the comparative tcriterion of Student. The average levels of the index for the concentration of attention from both groups are $31,16 \mathrm{~s}$ and $29,51 \mathrm{~s}$, respectively for the educational group and representative team (Table 2). The difference got is $d=1,42 \mathrm{~s}$. The percentage proportion of this difference is $\mathrm{d} \%=4,68$. The better indices of students from the basketball team by $\mathrm{P}(\mathrm{t})=48,96 \%$ have not been statistically confirmed, and we cannot speak of the reliability of the difference (Figure 2).

As regards the index steadiness of attention, the difference in the average levels of results is $\mathrm{d}=-0,08$. Percentage expression is $\mathrm{d} \%=7,82 \%$. It has to be noted the extremely high average achievement of the educational group on this index. It is only at one centesimal $(0,01)$ of the absolute achievement $(1,00)$, on this test of the values got. Despite the comparatively high value of $\mathrm{P}(\mathrm{t})=72,71 \%$, it doesn't give us ground to speak about statistically reliable differences, on this index (Figure 2).

\section{CONCLUSIONS}

The level of development and variability of indices for concentration and steadiness of attention has been established, with students from educational groups and representative basketball team at the UNWE. Values of the coefficient of variation define the aggregates as comparatively homogeneous on both indications, excepting the steadiness of attention with basketball players, whose coefficient of variability defines the group as heterogeneous.

1. Statistically reliable differences in the results from the investigation have not been established for both investigated indications.

2. To enrich the methods and continue applying exercises in the educational and especially in training classes for perfection and maintaining a high level of concentration and steadiness of attention, which qualities have been established as significant for the economic profession.

\section{REFERENCES}

1. Stavreva, I. Significant physical and intellectual qualities for experts in mining industry. Year-book of the University of Mining and Geology „St. Ivan Rilski“Sofia, v. 57, Roll IV: Humanitarian and Economic sciences", Publishing house "St. Ivan Rilski“", Sofia: 104-106, 2014.

2. Stavreva, I., S. Stavrev. Requirements to motor and intellectual qualities for experts from mining industry and economic profession and their comparison. International scientific conference „Pedagogical education - traditions and modern times“, VTU „St. st. Cyril and Methodius", Pedagogical faculty, Collection of reports. I \& B, Veliko Tarnovo: S4_12, 2015.

3. Stavreva, I. Possibilities for adaption of physical preparation of students to the requirements of the professional activity in mining industry. Year-book of the University of Mining and Geology „St. Ivan Rilski“- Sofia, Roll IV - Humanitarian and Economic sciences, v. 58, Publishing house "St. Ivan Rilski“, Sofia: 91-94, 2015.

4. Stavrev, S. Establishing and development of referent psycho-physical qualities, resulting from the professiogramme of economists. Dissertation, NSA"Vasil Levski“, Sofia, 2013.

5. Stavreva, I. Profession-applied effectiveness of Physical education and sports at the UMG "St. Ivan Rilski". News of "Foreign languages and sports" Department at the UMG "St. Ivan Rilski" Sofia, PH "St. Ivan Rilski", v. XIX/2019, Sofia: 32-42, 2019.

6. Iliev, I. Comparison of intellectual qualities of students, doing basketball and volleyball in Physical education classes, at the UE Varna. Sport and Science, Extra issue No.4, Sofia: p. 192-195, 2008.

7. Stavrev, S., P. Ivanov. Comparison of qualities of attention between students from basketball and volleyball teams in the UNWE-Sofia, Bulgaria. KNOWLEDGE International journal (Humanities) Vol.35, №6, Print GRAFOPROM- Bitola, Skopje: 2143-2147, 2019.

8. Moneva E., I. Barova. Comparative analysis of some psychological indicators for students from the unwe table tennis and mass aerobics classes. International Journal Scientific KNOWLEDGE -Papers VOL.30.2, Skopje: 473-476, 2019. 
9. Bozhkova, A., G. Dyakova, S. Stavrev. Distinctiveness of some characteristics of attention and effective thinking, with students from both higherschools. STUDIA UBB EDUCATIO ARTIS GYMN., LVIII, 1: $41-46,2013$.

10. Arsova, P. Concentration and steadiness of attention of volleyball players from the UNWE team, at the finals of students' championship. Third Scientific Conference "Contemporary trends, problems and innovations of physical education and sports at higher schools", Publishing complex -UNWE, Sofia: 49-55, 2017.

11.Rachev, K., N. Mateeva, Ts. Drazheva, V. Alipieva, B. Marinov, L. Petrov, P. Christoskov, V. Stoev. Theory and methods of physical education - part I and II. NSA PRESS, Sofia, 1998.

12.Tsvetkov, V. Complex approach at the preparation of basketball players. Research paper, NSA „V. Levski“, Sofia, 2006.

13.Gigova, V. Statistical processing and analysis of data. NSA Press, Sofia, 2006. 